\title{
Do We Need to Redesign the Current Assessment System in Bangladesh? A Review of Theory and Practice
}

\author{
Faieza Chowdhury \\ Southeast Business School, Southeast University \\ House.No, 64 Road No 18, Dhaka 1213, Bangladesh \\ E-mail: faiezac30@gmail.com
}

Received: October 7, 2019 Accepted: December 7, 2019 Published: December 15, 2019

doi:10.5296/gjes.v5i2.15585

URL: https://doi.org/10.5296/gjes.v5i2.15585

\begin{abstract}
In this current age of highly competitive global environment, teachers are under tremendous pressure to assess student learning in the most effective manner. Two tools that teachers commonly utilize to assess students in their classes are formative and summative assessment. In formative assessment, teachers gather data in order to improve student learning and in summative assessment they use the data to assess students' learning at the end of a specific course of study. The scores on both types of assessment should meet the minimum standards of both reliability and validity. In this article we highlight the differences between the two forms of assessment, discuss the theories pertaining to summative and formative assessment, identify how educators at tertiary level in Bangladesh commonly utilize the two types of assessment and disclose opinions of teachers regarding whether the current assessment system is appropriate or need any further improvements. Findings from the study indicate that most teachers have an incomplete and unharmonious understanding about assessment often failing to clearly distinguish between formative and summative assessments.
\end{abstract}

Keywords: Assessment, Summative, Formative, Theory, Practice, HEIs, Bangladesh 


\section{Introduction}

Assessment is a vital element in the education sector for both accreditation and learning purposes. Despite the extensive literature in formative and summative assessment, most teachers do not have a clear understanding of both the assessments. Scriven (1967) first made the distinction between formative and summative assessment. He states that assessment is a judgment based on certain specific weighted goals, yielding either comparative or numerical ratings. The processes of assessment are the steps that are needed to be taken in order to come to a specific judgment. Judgment cannot be made in a vacuum hence there must be some standards for comparison. One must also list down the criteria which are relevant for any specific judgment. According to Scriven (1967), assessment is an integral part of all aspects of daily life and it is a single process of making a judgment to standards, goals and criteria.

Formative assessment are the activities undertaken by the teachers in class to assess their students' learning which can then be used as a feedback to modify teaching and learning (Black \& Wiliam, 2010). According to Wiggins (1998), the aim of this type of assessment is to educate performance and not merely to audit it. This assessment provides teachers continuous flow of information about their current students' understanding level which can be used by teachers to adjust their teaching method and improve student learning. Formative assessment can help students to understand about what the learning goals are, where the student stand in relation to the learning goals and in what ways they can further improve their performance (Black \& Wiliam, 2010; Sadler, 1989). Although it is possible for teachers to grade the formative assessments such as quizzes but in general the scores delivered from such assessments are not factored into the final grading. This is because the main goal of formative assessment is to evaluate student understanding and teaching effectiveness. According to Cook (2009), formative assessments can be classified into two groups: (1) Spontaneous formative assessments and (2) Planned formative assessments. Planned formative assessments are activities such as quizzes, exercises and projects which are systematically assigned by the teacher in class to assess students' progress. On the other hand, spontaneous formative assessments are impromptu activities in the class such as after delivering a lecture, teacher may conduct a question and answer (Q\&A) session by randomly calling students and asking them about the concepts covered in the class. Regardless of the type of formative assessment applied in the classroom, the key is to assess current performance of the students, identify which teaching methods are working and what can be done to improve both students' and teachers' performance in the class.

Summative assessments are cumulative assessments which are used to evaluate what a student has learned or the quality of learning. These are high-stake assessments which are always graded, conducted less frequently and carried out only after completion of certain segments of instruction. Some common examples of summative assessments are final examinations, terms papers, entrance exams etc. Apart from assessing students' learning, summative assessments can also be used to assess whether students are eligible for enrolling in certain programs or qualifications (Harlen \& Gardner, 2010). Summative assessments should be conducted in ways which allow students to demonstrate both their conceptual knowledge of the subject and practical understanding of how to apply that knowledge in real 
world settings. Therefore summative assessments should include variety of questions including multiple-choice questions and performance-based-assessments so that students can demonstrate problem-solving skills, critical thinking along with the basic conceptual knowledge of the chosen subject matter. Due to the competitive labor market it is important for teachers to design the summative assessments in a way which will prepare students to succeed in entry-level careers. In that respect, performance-based assessments are one of the best forms of assessment because they require students to demonstrate their knowledge instead of simply parroting back memorized facts (Mc Tighe \& Ferrara, 1998).

In this paper we highlight the differences between formative and summative assessments, benefits of both the assessments, how both assessments are currently utilized by the teachers at tertiary level in Bangladesh and in what ways we can improve the current assessment techniques.

\section{Benefits of Formative and Summative Assessment}

\subsection{Formative Assessment}

It can be broadly defined as all activities undertaken by teachers to get feedback about students' learning which can be used diagnostically to alter teaching and learning. Fisher and Frey (2014) laid a foundation in which teachers can understand the importance of formative assessment system. This system consists of three parts: learning goals, student feedback and planning of student instruction based on identified weakness. When teachers discover in which areas students are having trouble then this information can be utilized to make any necessary adjustments to teaching and instructional approaches for improving class performance. Black and Wiliam (1998) conducted an extensive research to determine whether formative assessment increases academic standards. Their findings indicate that formative assessments produce significant learning gains; specifically it is highly beneficial to improve the performance of low-achieving students and students with learning disabilities.

Feedbacks from formative assessment can create awareness among the learners to realize what gaps exists between their desired goals and current knowledge (Ramaprasad, 1983; Sadler, 1989). In formative assessment, students get feedback on tests and homework from teachers which can help them to understand their errors and provide guidance on how they can improve performance in the future by correcting those flaws. Formative assessments are particularly helpful to lower achieving students as feedback from such assessment encourages them to work harder and improve their performance in the class. Formative assessment help support the expectations that all the children can learn to high levels and counteracts the cycle in which students attribute poor performance to lack of innate ability (Ames, 1992; Vispoel \& Austin, 1995). In formative assessment, the main goal is to understand what students already know in order to make adjustments to teaching and learning techniques later. Hence, teacher observation, classroom discussions are vital elements of formative assessments along with tests and homework. Formative assessment is highly linked to instructional practices. Therefore, it is vital for instructors to determine what type of classroom activities, assignments and tests will be adopted to achieve the learning objectives. Later the feedback from formative assessments will be used to improve teaching and learning. The Regional 
Educational Laboratory in 2017 conducted a review of twenty-three different studies to determine the impact of formative assessment on student learning. In this thorough review of studies, on average formative assessment had a positive impact on student academic achievements (Klute et al., 2017).

\subsection{Summative Assessment}

Teachers are required to undertake some form of summative assessment as a basis for reporting grades or meeting accountability standards. While formative assessment allow teachers to guide and monitor students' performance over time, summative assessments provide a snapshot of students' performance on a given test condition. Summative assessments are mainly used for grading purposes to enable comparisons between learners and to ensure that standards are met (Shute \& Kim, 2014). A summative assessment is a type of evaluation that allows instructors to judge the performance of students at the end of task or program. It ranges from a simple teacher-constructed end of class exam to standardized exams conducted for admission purposes Standardized assessments can provide objective data to support teachers' professional judgment, to make high-stake decisions and to bring adjustments to the curriculum which can ultimately improve the education process. This type of assessment enable students to apply what they have learned in the class as it requires them to retain the knowledge that they have acquired and solve various problems.

It is quite natural that in a class, some students will be ahead while others will lag behind. Summative assessments allow teachers to understand the current position of students in the class. It provides instructors a general overview of where the class stands as a whole. In this respect summative assessments can help instructors to identify learning and teaching gaps and make any necessary future adjustments. Certain summative assessments can also provide valuable data at national, district and global levels. The average scores from these assessments help policy makers to determine which academic institutions should be provided funding, which programs are more successful and whether curriculum changes are necessary for improvement in student learning.

Typically, the primary goal of summative assessment is to evaluate student learning, skill acquisition and academic achievements at the end of a chapter, unit etc. It can also guide administrators and educators to improve the current curriculum and teaching methodology. For instance when summative assessment clearly indicate that there are continuous gaps between learning goals and student knowledge then administrators may need to take actions in order to minimize this learning gap.

\section{Differences between Formative and Summative Assessment}

There are some key differences between formative and summative assessments as listed below:

\subsection{Purpose of Assessment}

In case of summative assessment, the main purpose is to evaluate students' achievement. After completion of a chapter or a course of study, the instructor may want to find out 
whether the learning goals are achieved. Hence teachers take tests and assign grades to evaluate students' performance. On the other hand, the main purpose of formative assessment is to improve students' learning by giving them meaningful feedback on their class performance. Here the tests are not conducted for generating grades but to steer the students in an upward direction by monitoring their class performance and identifying students' strengths and weaknesses. The main goal of formative assessment is to monitor students' performance and obtain feedback which can be used to improve teaching and learning.

\subsection{Timing of Assessment}

Generally, formative assessments are carried out during the learning process. For instance, a teacher may teach a new topic in the class and later ask some questions to his students in order to find out whether students understand the concepts clearly. Other common examples of formative assessment are summary writing, drawing of concept maps, one-minute paper, think-pair-share sessions etc. However, summative assessments are typically carried out after the learning process is complete. For instance, after a chapter is complete then the instructor may give an assignment to students where they have to use all the concepts covered earlier to answer the questions in the assignment. Other examples of summative assessments are final exams, reports, end-of-class projects. Summative assessments are always taken at the end of a course and they are often cumulative in nature which are designed to tests a student's long-term memory.

\subsection{Frequency and Weight of Assessment}

In case of formative assessment, the evaluation is carried out several times during the learning process. For instance, after every lecture teachers can carry out in-class games, group presentations and hands-on activities to monitor students' progress. Teachers do have greater independence and flexibility in conducting the formative tasks as the assessments are more frequent and holds very low marks or point values. However, the summative assessments are more structured and standardized. Generally, high weights are assigned on summative assessments and grades serve as a tool to evaluate students' progress at the end of the term. In case of summative assessments, teachers have less flexibility as the type of exams and percentage of weights are often set by the academic institutions.

In summary we can say that any assessment which is used to provide a feedback to the teacher about students' learning or understanding in class is usually a formative assessment. Whereas, any assessment which is used to get an evaluation score/grade of the students at a point in time is summative assessment.

\section{Methodology}

For this research we have collected data from 30 faculty members who are actively engaged in teaching at different higher academic institutions in Bangladesh. A questionnaire was designed which comprised of 10 questions for the purpose of conducting the interview. All the questions were open-ended and required verbal responses from the participants. Generally, the questions were clearly understood by all the participants and very few queries were raised. A sample questionnaire is provided in Appendix 1. 


\section{Findings and Discussions}

In questions 1 and 2, participants were asked to provide a rough definition of summative and formative assessment. 76\% (23 out of 30) respondents were successful in giving answers which were close to the correct definition. On the other hand, the remaining $24 \%$ of the teachers provided incorrect answers and some even failed to give any comment. In questions 3 and 4, teachers were asked to give at least one example of formative and summative task. $94 \%$ of the respondents noted that formative tasks include quiz and assignments whereas all respondents stated that summative tasks include term examinations. This is a clear indication that although faculties may lack the theoretical knowledge of formative and summative assessments but they do have the basic understanding of both types of assessment. In question 5, teachers were asked whether formative and summative assessments are interrelated. $84 \%$ (25 out of 30) responded that formative and summative tasks are related as some of the formative assessments contribute to summative assessments. In question 6 , faculties were asked whether they keep formative and summative assessments separate. $94 \%$ (28 out of 30) teachers stated that they do keep both assessments separate. Nevertheless, some teachers also point out that certain assessments are treated as both formative and summative as these assessments provide feedback to teachers about class performance and are also assigned scores to generate grades at the end of the semester. In questions 7 and 8 , teachers were asked whether they use formative and summative assessment to calculate grades. All the respondents agreed that they use both formative and summative assessments for grading purpose. This finding is surprising and contradicts with the theoretical aspects. We have already discussed earlier that formative assessments are not graded and they are mainly used to gain feedback on students' learning in the class and modify teachers' mode of teaching to improve future performances. Summative assessments are high-stake assessments which are always graded and compared against some predetermined standard or benchmark. Our findings indicate that although most teachers are aware about the differences between formative and summative assessments, but in practice most of the teachers are treating both types of assessments in similar fashion. Teachers are using both formative and summative assessment scores to derive final grades of students at the end of the semester. In question 9, teachers were asked whether they inform the students ahead regarding which tasks will be treated as formative and summative. All the respondents affirmed that they do notify their students at the beginning of the semester about the nature and the type of assessments which will be used for grading. This affirms our previous finding where we have discovered that teachers do have understanding of both type of assessment but in practicality both assessments are used for grading in a similar fashion. Both formative and summative assessments are graded by the teachers to generate the final scores at the end of the semester in Bangladesh. In question 10, teachers were asked whether they have attended any formal seminar, workshops or trainings on assessment. Only $8 \%$ of the respondents agreed that they have attended workshops on assessment and the remaining $92 \%$ respondents stated that they have received no such formal trainings. Moreover, all respondents do agree that trainings on assessment are necessary to enhance teachers' conceptual knowledge of formative and summative assessment so that they can critically apply this understanding to evaluate their students' learning and performance in a more effective manner. 


\section{Conclusion}

Learning and assessment are inextricably linked. Objectives, delivery and assessment are the cornerstones of any educational endeavor Kulasegaram and Rangachari (2018). This article reports the findings of a qualitative study evaluating teachers' understanding of formative and summative assessments at higher academic institutions in Bangladesh. Evidence collected from the selected participants of the study indicates that most of the teachers do not separate the formative and summative assessments for grading purposes and they also at times tend to use the summative assessments for formative purposes. This corroborates the findings of William (2000), as he states that in most countries very few teachers were able or willing to operate parallel assessment systems - one designed for summative function and another for formative purposes. Hence teachers often repeat and duplicate the assessment process.

The findings from our study indicate that in Bangladesh most of the teachers at tertiary level use both formative and summative assessments for grading their students. Formative assessment is concerned with judgment about the quality of student responses that can be used to shape and improve students' competence by short-circuiting the randomness and inefficiency of trial and error learning. Generally, formative assessments should not be graded and the main aim of this type of assessment is to provide feedback on performance by assessing the students' strengths and weaknesses. Results show that many teachers confuse formative and summative assessments at the tertiary level in Bangladesh. Nevertheless, there are some teachers who state that the whole point of formative assessment is gaining feedback from students so it loses this whole point when students are graded on formative assessments.

Hence to improve the assessment processes in Bangladesh it is vital for academic institutions to organize workshops and seminars for creating awareness on various types of teaching assessments. Teachers should be given the liberty to decide which type of formative and summative assessment techniques they wish to integrate in their classes. Providing a choice to the teachers is essential because it will allow teachers to select those specific assessment techniques which will be the best fit to their own model of teaching and harmonize to their individual personality. This will also permit the teachers to customize assessments according to the profile of students, type of classes and courses of study.

\section{References}

Ames, C. (1992). Classrooms: Goals, structures, and student motivation. Journal of Educational Psychology, 84(3), 261-271. https://doi.org/10.1037/0022-0663.84.3.261

Black, P., \& Wiliam, D. (1998). Assessment and classroom learning. Assessment in Education, 5(1), March, 7-74. https://doi.org/10.1080/0969595980050102

Black, P., \& Wiliam, D. (2010). Inside the black box: Raising standards through classroom assessment. Phi Delta Kappan, 92(1), 81-90. https://doi.org/10.1177/003172171009200119

Cook, H. G. (2009). Formative assessment: Best practices part 1. Retrieved from http://flareassessment.org/resources/PA_PD_Form_\%20Assess_Ppt_1_rev050709.pdf

Fisher, D., \& Frey, N. (2007). Checking for understanding: Formative assessment techniques 
for your classroom. Alexandria, VA: ASCD.

Harlen, W., \& Gardner, J. (2010). Assessment to support learning. In J. Gardner, W. Harlen, L. Hayward, G. Stobart, \& M. Montgomery (Eds.), Developing teacher assessment (pp. 15-28). New York, NY: Open University Press.

Klute, M., Apthorp, H., Harlacher, J., \& Reale, M. (2017, February). Formative assessment and elementary school student academic achievement: A review of the evidence. Washington, DC: Institute of Education Sciences. Retrieved from https://ies.ed.gov/ncee/edlabs/regions/central/pdf/REL_2017259.pdf

Kulasegaram, K., \& Rangachari, P. K. (2018). Beyond "formative": assessments to enrich student learning. Adv Physiol Educ, 42, 5-14. https://doi.org/10.1152/advan.00122.2017

McTighe, J., \& Ferrara, S. (1998). Assessing learning in the classroom. Burlingame. CA: National Education Association.

Ramprasad, A. (1983). On the definition of feedback. Behavioural Science, 28, 4-13. https://doi.org/10.1002/bs.3830280103

Sadler, D. R. (1989). Formative assessment and the design of instructional systems. Instructional Science, 18, 119-144. https://doi.org/10.1007/BF00117714

Scriven, M. (1967). The methodology of evaluation. In R. Tyler, R. Gagne and M. Scriven, Perspectives on Curriculum Evaluation (AERA Monograph Series - Curriculum Evaluation) Chicago, Rand McNally and Co.

Shute, V. J., \& Kim, Y. J. (2013). Formative and stealth assessment. In J. M. Spector, M. D. Merrill, J. Elen, \& M. J. Bishop (Eds.), Handbook of Research on Educational Communications and Technology (4th ed., pp. 311-323). Lawrence Erlbaum Associates, Taylor \& Francis Group, New York, NY. https://doi.org/10.1007/978-1-4614-3185-5_25

Vispoel, W. P., \& Austin, J. R. (1995). Success and failure in junior high school: A critical incident approach to understanding students' attributional beliefs. American Educational Research Journal, 32(2), 377-412. https://doi.org/10.3102/00028312032002377

Wiggins, G. P. (1998). Educative assessment: Designing assessments to inform and improve student performance. San Francisco, CA: Jossey-Bass.

Wiliam, D. (2000). Integrating summative and formative functions of assessment. Keynote address to the European Association for Educational Assessment, Prague: Czech Republic, November. Retrieved from http://www.kcl.ac.uk//depsta/education/hpages/dwliam.html 


\section{Macrothink \\ Global Journal of Educational Studies \\ ISSN 2377-3936 2019, Vol. 5, No. 2}

\section{Appendix 1. Sample Questionnaire}

1. Could you give a rough definition of formative assessment?

2. Could you give a rough definition of summative assessment?

3. Could you give an example of a formative task?

4. Could you give an example of a summative task?

5. Is formative assessment connected to summative assessment? If yes, then how is it related?

6. Do you treat formative and summative assessments separately?

7. Do you use summative assessments for calculating course end grades?

8. Do you use formative assessments for calculating course end grades?

9. Do you inform students regarding which assessments are formative and which ones are summative prior to the grading process?

10.Have you attended any formal seminars/workshops/trainings on assessment?

11.In what ways do you think the current assessment system can be improved?

\section{Copyright Disclaimer}

Copyright for this article is retained by the author(s), with first publication rights granted to the journal.

This is an open-access article distributed under the terms and conditions of the Creative Commons Attribution license (http://creativecommons.org/licenses/by/3.0/). 